\title{
Evaluation of Teachers' Performance of Vision Screening in Primary School Children in Port Harcourt
}

\author{
PN Tabansi ${ }^{1}$ MB;BS, FWACP, FMCPaed, IC Anochie ${ }^{2}$ MB;BS, FWACP, KEO Nkanginieme ${ }^{2}$ MB;BS, \\ FWACP, FMCPaed, CN Pedro-Egbe ${ }^{3}$ MB;BS, FMCOph \\ ${ }^{1}$ Department of Paediatrics, University of Port Harcourt Teaching Hospital, Port Harcourt, Rivers State, Nigeria \\ ${ }^{2}$ Department of Paediatrics and Child Health, University of Port Harcourt, Port Harcourt, Rivers State, Nigeria \\ ${ }^{3}$ Department of Ophthalmology, University of Port Harcourt Teaching Hospital, Port Harcourt, Rivers State, Nigeria
}

\section{SUMMARY}

Objective: To evaluate the ability of primary school teachers to perform simple vision screening on their school pupils, so as to determine if they can provide the first level of school vision screening services, and refer to the ophthalmologist for further evaluation when necessary.

Methods: Using a multi-stage sampling technique, 130 teachers were randomly selected from 13 schools in Port Harcourt Local Government Area of Rivers State. They were trained for six hours at a skills acquisition workshop on vision disorders in children and vision screening using Snellen visual acuity charts. Subsequently, they screened 1,300 of their pupils, who were all re-screened by the research team.

Results: One hundred and ten female $(84.6 \%)$ and 20 male teachers $(15.4 \%)$ participated in the study. Seventy $(53.8 \%)$ were from public schools while $60(46.2 \%)$ were from private schools. The sensitivity of the teachers' visual acuity test, compared to that of the research team, was $53.3 \%$, with a high specificity of $94.6 \%$. The positive and negative predictive values of the teachers' test were also high. The teachers' visual acuity measurements showed moderate agreement with that of the research team with a Kappa score of 0.604 .

Conclusion: The study concluded that trained primary school teachers can effectively perform vision screening in school children using Snellen visual acuity charts for early detection and treatment of vision disorders in school pupils.

Key words: primary school teachers, school children, vision

screening

\section{INTRODUCTION}

Visual impairment is a significant cause of morbidity in children worldwide. ${ }^{1}$ The World Health Organization
(WHO) reports that there are 1.5 million blind children worldwide, with two-thirds of these in Africa and Asia ${ }^{1}$. In these developing countries, $33 \%$ to $72 \%$ of blindness is preventable and treatable. ${ }^{1}$ Studies done across the world also reveal that $7.7 \%$ to $15.8 \%$ of children have reduced visual acuity, of which $50 \%$ to $72.5 \%$ is due to correctable refractive errors. ${ }^{2-6}$ In Nigeria, $1.7 \%$ to $10.2 \%$ of school children have various ophthalmic defects requiring attention. ${ }^{9-10}$ Undetected ocular disorders in children may lead to academic failure. ${ }^{11}$

The role of teachers as health educators is well established. ${ }^{12}$ There is a growing recognition that they can, with training, deliver simple health and screening services, and refer children for treatment if they have health problems. ${ }^{12}$ While it is recognized that teachers are not replacements for qualified health personnel, they can be trained to provide simple health services for school children, such as vision screening. ${ }^{12}$ Various studies ${ }^{13-14}$ have also shown that in resource-poor countries, where eye care specialists are unavailable, teachers can be trained to perform simple vision screening and refer school pupils for further care where necessary. One of such studies was carried out in Tanzania where trained school teachers could correctly identify $70 \%$ of pupils with bilateral poor eyesight, using visual acuity charts alone, with $91 \%$ specificity. ${ }^{13}$

Teachers have also been used for vision screening in India where an evaluation of vision screening of 5.4 million school children done by teachers, showed that they can effectively perform vision screening and refer those children with poor vision for refraction and corrective spectacles. ${ }^{14}$ Furthermore, primary vision screening by these teachers brought down the workload for ophthalmic assistants (who would have had to do the screening) to about a twentieth of its original size. ${ }^{14}$ If teachers can be trained to provide primary vision screening services for their pupils, it will serve the dual purpose of early detection and treatment of

*Correspondence: Dr. P.N. Tabansi, Department of Paediatrics, University of Port Harcourt Teaching Hospital, Port Harcourt, Rivers

State, Nigeria. P.O. BOX 6118 Port Harcourt • E-mail: petronillatabansi@yahoo.com 
vision disorders in children. It will also reduce the workload of eye care specialists in Nigeria.

\begin{abstract}
Aim
This study evaluates the ability of primary school teachers to perform vision screening in their school pupils so as to determine if they can provide primary school vision screening services.
\end{abstract}

\section{MATERIALS AND METHODS}

Teachers employed for the study were selected using a multi-stage sampling technique. The schools served as the framework for sampling, from which the teachers were selected. Thus, a list of all the primary schools (defined as schools for basic or elementary education for children from 6 -11 years, i.e from primary 1-6) in Port Harcourt LGA obtained from the Rivers State Ministry of Education served as the sample frame. Port Harcourt LGA has 139 government approved primary schools clustered into 3 primary school districts - Diobu, Township and Trans-Amadi which have 67,53 and 20 schools respectively; with a approximate ratio of $6: 5: 2$.

The schools within each district were further stratified into public and private schools.

- Diobu district has 35 public and 32 private schools

- Township district, 25 public and 28 private schools

- Trans-Amadi district, 11 public and 9 private schools

Based on the school ratio of 6:5:2; a total of 13 schools were selected for the study. They comprised 6 schools ( 3 public and 3 private); 5 schools ( 3 public and 2 private); and 2 schools (1 public and 1 private) selected by simple random sampling from Diobu, Township, and Trans-Amadi districts respectively.

At each selected school, 10 teachers were randomly selected from the list of teaching staff provided by the school.

The study was carried out over a four-week period from $25^{\text {th }}$ June to $20^{\text {th }}$ July 2007.

Ethical clearance for the study was obtained from the Research and Ethics Committee of the University of Port Harcourt Teaching Hospital (UPTH). Notification and permission to carry out the study were obtained from the Rivers State Ministry of Education and all the head teachers of the selected schools. Consent was obtained from all recruited teachers, and parents of the school children that were screened. The study was carried out by the investigators and 10 research assistants (medical doctors).

\section{Training of Teachers}

The teachers were trained at a six-hour skill acquisition workshop on common vision disorders in children, and how to use Snellen's alphabetic and tumble 'E' visual acuity charts. This training was done by the investigators.

The teachers were taught how to grade eyesight for each eye separately. This was done by occluding the eye that was not being tested, and then asking the examinee to read aloud the letters (optotypes) on the Snellen chart at a distance of 6 metres. They were taught how to measure this distance using a measuring tape, ensuring that the 6-metre point is marked on the floor with a chalk. The tested eye was scored based on whether or not the child can see at least 4 of 5 optotypes of the 6/18 line of the Snellen alphabet/tumble ' $E$ ' chart. If 4 of 5 optotypes of the $6 / 18$ line cannot be seen (i.e $\mathrm{VA}<6 / 18$ ) by either eye or both eyes, the affected child is said to have a vision problem and graded as having a 'bad eye'.

There were practical demonstrations by the instructors including demonstrations of common errors, e.g, ensuring that the child understands the instructions before testing, and ensuring complete occlusion of the eye not being tested. Then, there were more practical demonstrations where the teachers practised on each other until full competence was attained.

Each teacher recruited for the study independently performed a visual acuity test on 10 of his/her class pupils who were randomly selected from the class register, using a table of random numbers. Testing was done in a well-lit (preferably natural light) area such as the school hall, or any other free room made available by the school; and their findings recorded on a Vision Screening Score Chart provided for them. Those who failed the screening test were given referral notes (to the ophthalmologist in UPTH) for pupils. The teachers were not given any monetary remuneration for participating, to avoid bias.

After the teachers were done with the screening of 1,300 pupils (10 pupils per teacher), members of the research team (the investigators and 10 other doctors who acted as research assistants) independently repeated the visual acuity test, using the same charts, on the same pupils as the teachers.

The doctors' results were used as reference standard to calculate the sensitivity, specificity, positive and negative predictive value of the teachers' visual acuity test using the following formulae: ${ }^{15}$

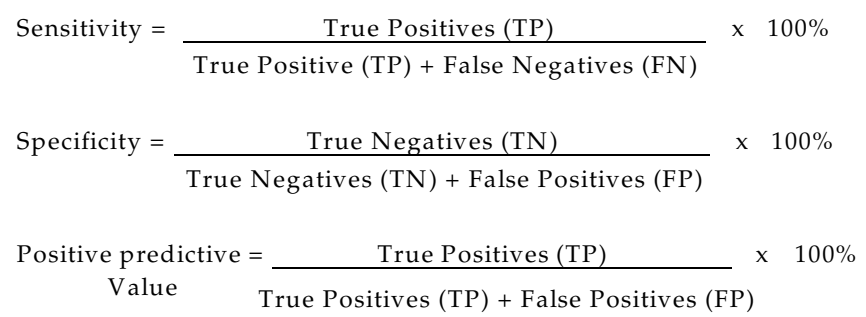


The Kappa score for the combined visual acuity tests for the right and left eyes was also calculated to test the level of agreement between the teachers' and the research team's results.

The doctors' results were also used to calculate the prevalence of low vision (VA $<6 / 18$ ) in the screened school children.

Data were analysed using EPI info version 6 and SPSS 11.0. Comparison of subgroup was done using the chi-square test. Statistical significance at $95 \%$ confident interval is $\mathrm{p}<0.05$.

\section{RESULTS}

All the 130 recruited teachers participated in the study. There were 110 female $(84.6 \%)$ and 20 male teachers $(15.4 \%)$. Seventy teachers $(53.8 \%)$ were from public schools while 60 $(46.2 \%)$ were from private schools.

\section{Comparison of Results of Visual Acuity Screening by Teachers and the Research Team}

The research team's visual acuity screening results were used as the reference standard to which the teachers' visual acuity testing was compared. Table 1 gives a summary of the combined left and right eyes VA results of pupils identified as having a 'good eye' (VA of 6/18 or better), and a 'bad eye' $(\mathrm{VA}<6 / 18)$ by the teachers and the research team.

A total of 1,300 children screened by the teachers were all re-screened by the research team. One thousand, one hundred and sixty-three pupils $(89.5 \%)$ were identified to have 'good eyes' (VA of $6 / 18$ or better) by the doctors' screening. Out of these, the teachers correctly identified 1144 (98.3\%) (True Negatives -TN). Similarly, 137 (10.5\%) pupils had 'bad eyes' $(\mathrm{VA}<6 / 18)$ by the doctors' screening, of which the teachers correctly identified 73 (53.3\%) (True positives - TP - table 1).

Using table 1, the Kappa score for both eyes was thus calculated to be $0.604(\mathrm{p}=0.000)$ indicating a moderate agreement between the doctors' and teachers' visual acuity tests.

Also from table 1, using the research team's results, the prevalence of reduced vision $(\mathrm{VA}<6 / 18)$ was calculated to be $10.5 \%$ ( i.e., 137 pupils with VA $<6 / 18$ out of the total study population of 1,300 pupils).

Table 2 shows the sensitivity, specificity, positive and negative predictive values of the teachers' visual acuity test, using the research team's results as the gold standard. The teachers achieved a sensitivity of $53.3 \%$ with a specificity of $98.4 \%$ (table 2).
Table 1. Comparison of teachers' and research team's visual acuity test of pupils

\begin{tabular}{|c|c|c|c|c|}
\hline \multirow{5}{*}{$\begin{array}{l}\text { RESEARCH } \\
\text { TEAM } \\
\text { VA } \\
\text { RESULT } \longrightarrow\end{array}$} & \multicolumn{4}{|c|}{$\begin{array}{c}\text { TEACHERS' VA RESULT } \\
\downarrow \\
\downarrow\end{array}$} \\
\hline & & $\begin{array}{c}\text { No of pupils } \\
\text { with } \\
\text { 'GOOD EYE' }\end{array}$ & $\begin{array}{c}\text { No of pupils } \\
\text { with } \\
\text { 'BAD EYE' }\end{array}$ & TOTAL \\
\hline & $\begin{array}{l}\text { No of pupils } \\
\text { with } \\
\text { 'GOOD } \\
\text { EYE' }\end{array}$ & $1144(\mathrm{TN})$ & $19(\mathrm{FP})$ & 1163 \\
\hline & $\begin{array}{l}\text { No of pupils } \\
\text { with } \\
\text { 'BAD EYE' }\end{array}$ & $64(\mathrm{FN})$ & $73(\mathrm{TP})$ & 137 \\
\hline & TOTAL & 1208 & 92 & 1300 \\
\hline
\end{tabular}

Table 2 shows the sensitivity, specificity, positive and negative predictive values of the teachers' visual acuity test, using the research team's results as the gold standard. The teachers achieved a sensitivity of $53.3 \%$ with a specificity of $98.4 \%$ (table 2).

Table 2. Sensitivity, Specificity, Positive and Negative Predictive Value of teachers' visual acuity test

PARAMETER

FORMULA USED

RESULT

Sensitivity

$\frac{73=-}{73+64} \times 100 \%$

$53.3 \%$

Specificity

$$
\frac{1144+=}{1144+19} \times 100 \%
$$

$98.4 \%$

Positive Predictive $\frac{73}{73+19} \quad \times 100 \%$

$79.3 \%$ Value

$$
\frac{1144}{1144+64} \times 100 \%
$$

$94.7 \%$

Negative Predictive Value

\section{DISCUSSION}

This study has demonstrated that trained primary school teachers can effectively perform vision screening in their school children. Specifically, the teachers are able to detect $53.3 \%$ of children with reduced vision when compared to the research team. This result compares favourably with a study done in Kariapatti, India by Nirmalan et al., ${ }^{16}$ in which a sensitivity of $50 \%$ for visual acuity testing was observed by community workers when compared to that of the ophthalmologists. In that same study, the sensitivity of the community workers' vision screening increased to $80.1 \%$ when visual acuity testing was combined with asking the 
child if he/she had eye problems. Wedner et al. ${ }^{13}$ also recorded a higher sensitivity of $70 \%$ for visual acuity testing by teachers in rural schools in Tanzania; with sensitivity also increasing to $80 \%$ when the VA testing was combined with asking the pupils about eye problems.

In Kaduna, Nigeria, Abubakar and Ajaiyeoba ${ }^{17}$ trained school teachers to perform VA test using an ' $E$ ' chart with only the 6/12 line of the Snellen VA chart, and observed a sensitivity of $59.1 \%$; while Limburg et al. ${ }^{14}$ in India got a higher value of $71 \%$ sensitivity for teachers vision screening using a teachers' card (a white card with four ' $E$ ' optotype of a size conforming to $6 / 9$ of the Snellen VA chart). The differences in sensitivity compared with the present study may be due to variations in methodology and definitions used, as this study trained teachers to use a lower cut-off of $\mathrm{VA}<6 / 18$ as being abnormal, thus reducing the sensitivity of the test, when compared to the more stringent criteria of VA $<6 / 12$ for the Kaduna ${ }^{17}$ study, and VA $<6 / 9$ in the India ${ }^{14}$ study. Also, the regular Snellen alphabet and Tumble ' $\mathrm{E}$ ' charts used for screening in this study are more time consuming, and thus more tedious, when compared to the less tedious and faster modified charts with only 4 to 5 ' $\mathrm{E}$ 's used in the other studies. ${ }^{14,16}$ This may have contributed to the comparatively lower sensitivity observed in the present study. The sensitivity of $53.3 \%$ from this study, though commendable, may be improved upon by training the teachers to combine the Snellen VA chart screening with inquiry about eye problems in the pupils, as was observed in the Kariapatti ${ }^{16}$ and Tanzanian ${ }^{13}$ studies.

The specificity of the teachers' visual acuity test when compared to the research team's was $98.4 \%$. This result agrees with studies done in Lagos, ${ }^{17}$ Tanzania, ${ }^{13}$ and India, ${ }^{14}$ where specificity of $85.1 \%, 93 \%$ and $94 \%$ respectively; demonstrating that teachers are able to identify children with normal vision to a high degree of accuracy.

The positive predictive value of the teachers' Snellen visual acuity test in this study was $79.3 \%$, suggesting that over three quarters of the children identified by the teachers as having reduced visual acuity actually had a vision disorder. The negative predictive value of the teachers test was $94.7 \%$ suggesting that almost all the children identified by the teacher as having a normal visual acuity as stipulated, had no vision disorder. This compares favourably with another studies done in Nigeria ${ }^{17}$ by Faderin and Ajaiyeoba in which a low positive predictive value of $47.4 \%$ with higher negative predictive value of $97.9 \%$ was observed.

The school health programme, under the auspices of the school health services, provides for routine medical examination of children at school entry, and at regular intervals thereafter until completion. ${ }^{18}$ This school medical examination is able to detect up to $15 \%$ of defects (mainly vision and hearing related) present in school children at the initial examination, in places where it is routinely done. ${ }^{18}$ The school health programme is not functional in many developing countries, including Nigeria; and as such, there is no established vision screening programme for children on commencement of school. ${ }^{8}$ This lack of a functioning school health programme may be responsible for the prevalence $(10.5 \%)$ of reduced vision observed in the primary school children screened in this study, and the average performance of vision screening by the teachers.

\section{CONCLUSION}

This study has demonstrated competence of trained primary school teachers at performing simple vision screening. Thus, they can used as a cost effective, feasible and sustainable means of ensuring primary school vision screening services for school children; for early detection and treatment of vision disorders, in the context of the school health programme.

\section{RECOMMENDATION}

In order to improve on the teachers' skill at vision screening, re-training at regular intervals may be necessary.

\section{ACKNOWLEDGEMENTS}

We wish to thank Petronella Nig. Ltd for their sponsorship of this research. We also acknowledge the contributions of the Rivers State Ministry of Education, all head teachers and teachers of selected schools, towards the smooth conduct of this survey.

\section{REFERENCES}

1. Gilbert C, Foster A. Childhood blindness in the context of VISION 2020 - 'The right to sight.' Bull World Health Org 2001; 79(3).

2. Zhao J, Pan X, Sui R, Munoz SR, Sperduto RD, and Ellwein L. Refractive error study in children, results from Shunyi District China. Am J Ophthalmol 2000; 129: 427-435.

3. Maul E, Barroso S, Munoz SR, Spertudo RD, Ellwein LB. The refractive error study in children: Result from La Florida, Chile. Am J Ophthalmol 2000; 129: 445-454.

4. Pokharel GP, Negrel AD, Munoz SR, Ellwein LB. Refractive error study in children: Results from Mechi Zone, Nepal. Am J Ophthalmol 2000; 129: 436444.

5. Chaturvedi S, Aggarwal OP. Pattern and distribution of ocular morbidity in primary school children of rural Delhi. Asia Pac J Public Health 1999; 11: 30-33.

6. Limburg H, Kansara HT, d'Souza S. Result of school eye screen of 5.4 million children in India. Acta Ophthamol Scand 1999; 770: 310-314.

7. Gordon YJ, Mokete M. Screening of pre-school and school children for ocular anomaly in Lesotho. J Trop Med Hyg 1982; 85: 135-137. 
8. Kuwama M, Mayeku R. A survey of prevalence of refractive errors among children in lower primary schools in Kampala district. Afr Health Sci 2002; 2: 69-72.

9. Abiose A, Bhar IS, Allanson MA. The ocular health of postprimary school children in Kaduna, Nigeria: Report of a survey. J Pediatr Ophthalmol Strab 1980; 17(5): 337-340.

10. Nwosu SNN. Ocular problems of young adults in rural Nigeria. International Ophthalmol 1998; 22: 259-263.

11. Ayed T, Sokkah M, Charfi O, El Matri L. Epidemiologic study of refractive errors in school children in socioeconomically deprived regions in Tunisia. J Fr Ophthalmol 2002; 25: 712-717.

12. Hall A, Adjei S, Kihamia C. School Health Programs. Afr Health 1996; 180: 22-23.

13. Wedner SH, Ross DA, Balira R, Kaji L, Foster. A. prevalence of eye diseases in primary school children in a rural area of Tanzania. Br J Ophthamol 2000; 84: 1291-1297.

14. Limburg H, Vaidyanathan K, Dalal HP. Cost-effective screening of school children for refractive errors. World Health Forum 1995; 160: 173-178.

15. Grimes DA, Schutz KF. Uses and abuses of screening tests. Lancet 2002; 359: 881- 884 .

16. Nirmalan PK, Vijayalakshmi P, Sheeladevi S, Kothari MB, Sundaresan K, Rahmathullah L. The Kariapatti pediatric eye evaluation project: Baseline ophthalmic data of children aged 15 years or younger in Southern India. Am J Ophthalmol 2003; 136: 703-709.

17. Faderin MA, Ajaiyeoba AI. Refractive errors in primary school children in Nigeria. Nig J Ophthalmol 2001; 9: 10-14.

18. Akani NA, Nkanginieme KEO. The school health program In: Azubuike JC, Nkanginieme KEO. (Eds.) Pediatrics and Child Health in A Tropical Region. Owerri, Nigeria: African Educational Services, 1999: 510-511. 